\title{
Development and Pretesting of a New Functional-Based Health Literacy Measurement Tool for Chronic Obstructive Pulmonary Disease (COPD) and Asthma Management
}

This article was published in the following Dove Press journal:

International Journal of Chronic Obstructive Pulmonary Disease

Iraj Poureslami, ,,2 Jessica Shum, ${ }^{1,2}$ Jacek Kopec, ${ }^{3}$ Richard Sawatzky, (iD) ${ }^{4}$ Samir Gupta, ${ }^{5}$ Smita Pakhale, (D) ${ }^{6}$ Saron Kassay, ${ }^{1,2}$ Kassie Starnes, ${ }^{1,2}$ Alizeh Akhtar, ${ }^{2}$ J Mark FitzGerald ${ }^{1,2}$

On behalf of the Canadian Airways Health Literacy Study Group

'Division of Respiratory Medicine, Department of Medicine, Institute for Heart and Lung Health, The University of British Columbia, Gordon and Leslie Diamond Health Care Centre, Vancouver, BC V5Z IM9, Canada; ${ }^{2}$ Centre for Clinical Epidemiology and Evaluation, Vancouver Coastal Health Research Institute, The University of British Columbia, Vancouver, BC V5Z IM9, Canada; ${ }^{3}$ Division of Epidemiology, Biostatistics, and Public Health Practice, School of Population and Public Health, The University of British Columbia, Vancouver, BC V6T IZ3, Canada; ${ }^{5}$ School of Nursing, Trinity Western University, Langley, BC V2Y IYI, Canada; ${ }^{5}$ Division of Respirology, Department of Medicine, St. Michael's Hospital, Toronto, ON M5B IW8, Canada; ${ }^{6}$ Ottawa Hospital Research Institute, University of Ottawa, Ottawa, ON KIH 8L6, Canada

Correspondence: J Mark FitzGerald Division of Respiratory Medicine, Department of Medicine, Institute for Heart and Lung Health, The University of British Columbia, Gordon and Leslie Diamond Healthcare Centre, The Lung Centre, 7th Floor, 2775 Laurel Street, Vancouver, BC V5Z IM9, Canada $\mathrm{Tel}+$ I 6048754 I 22

Email mark.fitzgerald@vch.ca
Background: Health literacy (HL) is a person's ability to practically apply a wide range of cognitive and non-cognitive skills in health-related decisions. HL includes five domains: navigate/ access, understand, communicate, evaluate, and use of health information and services. Currently, no tool accurately captures and measures HL in adult patients with asthma and COPD, while utilizing all 5-HL domains.

Objective: Develop a comprehensive functional-based measurement tool for adult asthma and/or COPD patients, while assessing HL on routine actions required to manage their chronic respiratory condition(s).

Methods: We developed our HL tool based on a conceptualization of the link between HL and asthma and COPD management, during needs assessment stage including; a systematic review, which was followed by patient-oriented focus groups, and key-informant and respirologist interviews. Preliminary face and content validation were obtained by patients' and health professionals' input prior to the pretesting stage. The needs assessment information enabled us to develop passages in scenario-format and corresponding items to assess HL core domains, in addition to numeracy skills, across nine self-management topics: peak flow meters, prednisone use, pulmonary rehabilitation, action plans, flu shots, inhaler technique, lifestyle (nutrition and exercise), trigger control, and map navigation. The tool was pretested with asthma and COPD patients to assess its relevance, clarity, and difficulty.

Results: Our systematic review identified the deficiencies of existing HL tools that assessed the HL skills of asthma and COPD patients. The patient-oriented focus groups $(n=93)$ enabled us to identify self-management topics and develop items for our proposed HL tool, which were enriched by input from 45 key informants (eg, policy makers, clinicians, etc.) and 17 respiratory physicians. Preliminary pretesting with a new cohort of participants (36 asthma and COPD patients and 39 key informants) aided in the refinement and finalized our tool. The modified tool included passages and corresponding items related to asthma and COPD management was pretested with 75 asthma/COPD patients who completed the questionnaire and provided their feedback on the clarity, relevance, and difficulty of the tool. The main barrier to self-management pertained to "communication" skills. The flu shot was the most relevant topic (91.2\%), while map navigation was the least relevant $(63.9 \%)$. Action plans were the most difficult topic, where only $55 \%$ knew when to utilize their action plans. Numeracy items challenged COPD patients the most.

Conclusion: We summarized findings from the development and preliminary testing stages of a new asthma/COPD HL tool. This tool will now be validated with a new cohort of patients. 
Practice Implications: Knowledge gained in this study has been applied to the final version of the tool, which is currently being validated.

Keywords: COPD and asthma management, health literacy, measurement tool, functional skills

\section{Introduction}

In 2009, the Canadian Expert Panel on Health Literacy conceptualized a five-domain model, defining health literacy (HL) as the degree to which individuals can access, understand, communicate, appraise, and use information to engage with the demands of different health contexts, to promote and maintain good health across the life-course. ${ }^{1}$ Although HL has been identified as one of the major determinants of health by the World Health Organization (WHO) and other health agencies, ${ }^{2-4}$ there is still much work to be done on integrating HL into the research and practice of health-care systems. This is attributable to the large number of people having low levels of general literacy and HL, according to the Public Health Agency of Canada $\mathrm{F}(\mathrm{PHAC}) ;{ }^{5}$ paradoxically, educational information/materials directed towards patients are developed at a reading level that is too high for most to comprehend. ${ }^{1,2}$ Disadvantaged patients (low socioeconomic status, the elderly, and minority groups) with chronic conditions are more likely to have low HL, which is associated with numerous negative health outcomes. ${ }^{6}$ Conversely, a recent systematic review found that improved HL was associated with better health outcomes and lower costs for both patients and the healthcare system. ${ }^{7}$ In addition, recent literature recognizes that proper chronic disease management is the preferred strategy for addressing the rising levels of chronic respiratory diseases. ${ }^{8,9}$ Such a strategy can be improved through enhancing HL skills of patients, as well as better understanding the link between internal (personal beliefs and perceptions) and external (availability and accessibility of health information and care services) factors associated with health outcomes. $^{6}$

Asthma and chronic obstructive pulmonary disease (COPD) are globally the most common chronic respiratory diseases. ${ }^{10,11}$ Asthma affects people of all ages and is characterized by recurrent episodes of wheezing, breathlessness, chest tightness, and coughing, ${ }^{12}$ while COPD is classified as chronic airflow limitation that is generally progressive and not fully reversible. ${ }^{13}$ Therefore, selfmanagement strategies are normally recommended by clinicians for patients to manage episodic worsening of these chronic conditions. ${ }^{14,15}$ As evidenced by different studies, there is an association between inadequate $\mathrm{HL}$ and poor asthma and COPD self-management practices (eg, identifying and monitoring triggers and symptoms, correctly using medications, and responding to worsening in symptoms as instructed by a physician or certified educator). ${ }^{16-18}$ However, most prior HL intervention studies applied generic measurement tools that have been widely criticized for their limited capacity to adequately measure all HL domains. Many of the existing HL assessment tools are not disease-specific, measure self-rated (self-perceived ability) HL skills and mainly assess "knowledge" or "general literacy" skills. Therefore, existing tools lack the capacity to measure the diverse skills required by a patient to properly manage their disease. ${ }^{19-21}$ Different studies emphasize on the need for the development of function-based HL tools, which measure actual ability to apply HL skills. ${ }^{17,18,22,23}$ Functional HL has been defined as a term to describe basic HL skills that are sufficient for individuals to obtain relevant health information and to be able to apply that knowledge to a limited range of activities. ${ }^{24}$ Functional-based measurement tools put patients in real-world situations and assess how they would act and perform in real-life situations, rather than what they perceive/imagine being capable of acting, which is mainly utilized in the existing self-rated tools. ${ }^{25,26}$ Therefore, a functional-based HL measurement tool can help to identify specific HL skill(s) that require improvement and can facilitate the conduction of practical interventions to address these gaps. ${ }^{25-27}$ To our knowledge, there is currently no function-based measurement tool that assesses the HL and self-management skills/abilities of adult asthma or COPD patients. In the context of the purpose of our study, we aimed to find out whether engaging patients and health professionals in the identification and generation of self-management topics can enable us to develop pool of items that facilitate the development of a comprehensive functional-based HL tool to assess HL skills of adult asthma and COPD patients?

\section{Methods}

Data for the conceptualization and development of our HL tool were derived from the following needs-assessment stages (Figure 1): (1) A systematic review of 65 asthma 


\section{Systematic Review:}

Conducted a systematic review in 2015 of existing asthma and COPD HL measurement tools to assess their comprehensiveness, disease related relevance and whether they included the 5-HL domains and numeracy

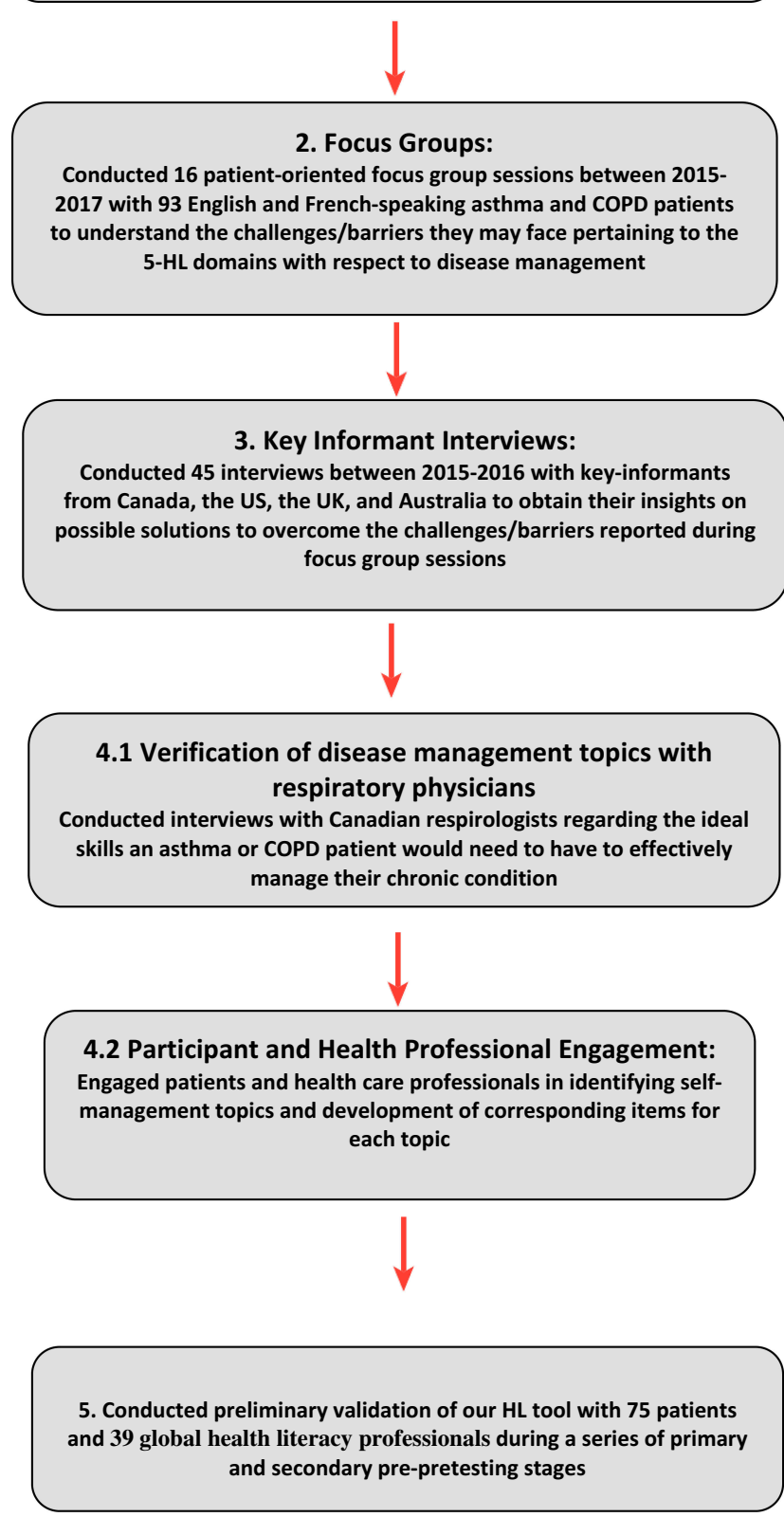

Figure I Conceptualization asthma and COPD disease management health literacy tool: Needs assessment stages.

and COPD HL measurement tools occured in 2015 to assess previous tools' comprehensiveness, disease-related relevance, and whether/how they included the 5 core HL domains; (2) 16 patient-oriented focus groups were conducted with 93 patients across Canada in 2015-2016 to understand the challenges/barriers pertaining to the 5-HL domains with respect to self-management practices; (3) 45 key-informant interviews (in-person or via telephone or
Skype) were conducted with health-care professionals, researchers, and policymakers from Canada, the US, the UK, and Australia to obtain their insights on possible solutions to overcome the challenges/barriers and reviewed self-management topics reported during focus group sessions; (4-1) interviewed 17 Canadian respirologists regarding the ideal functional HL skills asthma and/ or COPD patient should possess to effectively manage 
their disease; (4-2) The patients and health professionals helped in identifying self-management topics and the development of corresponding items for each topic, in addition to their preliminary face and content validation of our HL tool during the needs assessment stages. and (5) pretested the tool among 75 patients' across Canada (19 COPD and 56 asthma) (Figure 1).

\section{Ethics Approval}

Ethics approval was obtained from the University of British Columbia Clinical Ethics committee (as the principal investigator (PI) institution), as well as the research ethics boards from the collaborating sites that contributed during the different stages of the research project (see Supplementary Table 1. Summarizing the ethics committee name and project number for the collaborating centres).

\section{Systematic Review}

We conducted a systematic review of 2805 published articles in English to obtain a detailed overview of existing HL measurement tools to determine whether there was any research that applied all $5 \mathrm{HL}$ domains on self-management topics among adult asthma and COPD which has been published. $^{25}$

\section{Patient-Oriented Focus Groups}

We conducted 16 group sessions with 93 English and French-speaking adult asthma and COPD patients. The patients were recruited between 2015 and 2017. The group sessions were facilitated by experienced research staff at each site. Upon providing written consent, the participants were asked to share their understanding in terms of challenges/barriers that they faced with regards to self-management of their health condition. The responses were then categorized into the 5 HL domains and numeracy. The aim of the group session was to gain knowledge about the challenges faced by patients, as well as the disease management topics found to be most relevant to include in our proposed HL measurement tool. ${ }^{28}$ Each group session lasted between 60 and 90 mins, and the discussions were taped, transcribed, and translated (French sessions into English), before being analyzed using the NVivo statistical software (QSR International, version 11) at the Vancouver site. Each patient received $\$ 25$ as an honorarium to cover transportation and/or parking costs during the focus group sessions and pretesting stage.

\section{Key-Informant Interviews}

Between 2015 and 2016, 54 national and international key informants were invited to provide their insights in an interview setting. Forty-five subjects (15 males, 30 females) responded to our request and were interviewed. The key informants were introduced to the study by the research team. Consent form was obtained via in-person or by the e-mail. The key informants were health-care professionals $(\mathrm{n}=28)$; HL and community-based researchers $(\mathrm{n}=14)$; and policymakers $(\mathrm{n}=3)$. During the interviews, they were asked to provide potential feasible and practical solutions to the identified challenges and barriers mentioned by our focus group participants, as well as provide their comments on the disease management topics suggested by the patients. ${ }^{29}$ The solutions proposed by the key informants were used to develop answers and responses for the HL tool items. The key informants did not receive an honorarium for their participation.

\section{Further Verification of Disease Management Topics with Respiratory Physicians}

To further verify the disease management topics, and identify the clinical relevance of the topics identified by the patients and key informants, a number of opinion leaders, in the respiratory field across Canada were recruited to participate. ${ }^{20,21}$ The respiratory members of the study team identified the opinion leaders $(\mathrm{n}=23)$ who had extensive clinical and research expertise. The identified individuals were reached through email, and 17 (4 females, 13 males) expressed an interest to participate. The participants were asked, via email, to review and verify the self-management topics and corresponding items in the form of key functional skills a patient should possess, to optimally manage their disease. $^{30}$

\section{Final Stage of Item Generation}

After applying the inputs from the patient and professional groups in the development of our HL tool, two new previously involved patient groups were recruited and were asked to review and comment on the developed topics and tool items. Both patient cohorts were recruited from the Vancouver site and provided informed consent. Initially, 13 patients (8 asthma and 5 COPD) were invited for preliminary assessment sessions to review all passages and corresponding items for each self-management topic contained within our tool. The participants provided general suggestions and comments on the story-format scenarios developed for each self-management topic in the previous 
stages. The second cohort of patients (9 COPD and 14 asthma) was then asked to provide suggestions to improve the preliminary version of the tool in terms of formatting, relevance, and practicality. Lastly, the passages and related items for each topic were revised and organized by a professional adult patient educator to improve the tone and presentation of the items in our tool for each topic. At the final stage before the piloting with a large national sample, the preliminary version of the tool was further assessed during a pretesting stage by 75 ( 28 males, 47 females) asthma $(\mathrm{n}=56)$ and $\operatorname{COPD}(\mathrm{n}=19)$ patients from 3 specialty clinics for relevance, clarity, and difficulty. These participants were recruited in each collaborating specialty clinics by the direct involvement of co-investigators. At each site, experienced research staff obtained informed consent and then conducted the pretesting stage and. The collected data were then transferred to the Vancouver site via a secure channel (Dropbox) for data entry and analysis.

\section{Coding, Scale Development, and Analysis of Qualitative Data}

Data coding and scale development of the information collected during the need-assessment stages were conducted $^{31-33}$ with NVivo software. Content analysis to make replicable and valid inferences by interpreting and coding textual material ${ }^{32}$ was also applied to categorize the information shared by patients and key informants into the development of the content for the proposed tool, both in scenario format and individual items. The coding process (explained in detail in our recent publications ${ }^{28,29}$ ) helped to identify 13 main codes and 28 sub-codes (Table 1). The codes covered the $5 \mathrm{HL}$ domains and the numeracy skill attributed to self-management topics.

\section{Item Generation}

Once the HL domains were outlined, the item generation process began for identifying appropriate questions by applying an inductive method. ${ }^{34}$ Such an approach enabled us to use the information collected during patients' focus groups and individual interviews to inductively identify needed items for our HL tool. ${ }^{35}$ The aim was to develop relevant items for our tool that were across the entire continuum of $\mathrm{HL}$ and disease management competency. Items assessing functional HL skills were based on passages (scenarios), presented in either written or pictorial format, for each disease management topic. The item generation process ended with the creation of a matrix of 457 items that
Table I Main Codes and Sub-Codes

\begin{tabular}{|c|c|}
\hline Main Codes & Sub-Codes \\
\hline Beliefs & Health Domains \& Numeracy \\
\hline \multicolumn{2}{|l|}{ Definition of Health Literacy } \\
\hline Domains of Health Literacy & $\begin{array}{l}\text { - Access } \\
\text { - Understand } \\
\text { - Evaluate } \\
\text { - Communicate } \\
\text { - Use } \\
\text { - Numeracy }\end{array}$ \\
\hline \multicolumn{2}{|l|}{ Domain of Importance } \\
\hline Domain to add & $\begin{array}{l}\text { - New domain mentioned } \\
\text { - No domains to add }\end{array}$ \\
\hline $\begin{array}{l}\text { Factors Influencing } \\
\text { Experiences }\end{array}$ & $\begin{array}{l}\text { - Direction of influence } \\
\text { - Types of factors }\end{array}$ \\
\hline \multicolumn{2}{|l|}{ Measurement tool } \\
\hline \multicolumn{2}{|l|}{ Motivation } \\
\hline \multicolumn{2}{|l|}{ Navigation Question } \\
\hline Self-Management & $\begin{array}{l}\text { - Action or management plan } \\
\text { - Goals and goal setting } \\
\text { - Inhaler use } \\
\text { - Lifestyle changes } \\
\text { - Other self-management strategies } \\
\text { - Prescription drugs }\end{array}$ \\
\hline Experience with People & $\begin{array}{l}\text { - Advocacy by patient } \\
\text { - Relationship with others and sup- } \\
\text { port received }\end{array}$ \\
\hline $\begin{array}{l}\text { Experience with non-person } \\
\text { media }\end{array}$ & $\begin{array}{l}\text { - Official or validated sources } \\
\text { - Online resources } \\
\text { - Pamphlets, brochures, books } \\
\text { - Videos and multi-media sources }\end{array}$ \\
\hline Improving Health Literacy & $\begin{array}{l}\text { - Health-care provider improvement } \\
\text { - Healthcare system improvement } \\
\text { - Informational materials and methods } \\
\text { - Patient improvement } \\
\text { - Regional, provincial, or national } \\
\text { - } \text { strategies to improve } \\
\text { - Who is responsible for improvement }\end{array}$ \\
\hline
\end{tabular}

included self-management topics across 5 HL domains (plus numeracy), which, were used as the foundation framework for our proposed HL tool. The items were then classified into two categories: general respiratory disease management (seven topics) and disease-specific topics (two topics each for asthma and COPD) (Figure 2A and $\mathrm{B}$ ). A situational judgment format ${ }^{36}$ was applied to 


\section{A General Self-management topics}

\section{Puffer Uses}

- The correct technique and order of steps

- The correct doses (e.g. total number of puffs)

- Timing of doses (e.g. duration between puffs)

- When to get a refill

- Differences between "controller" and "reliever" and when to use which one

\section{Prednisone}

- The correct doses (e.g. total number of pills)

- The correct duration of doses using a calendar

- The term "medication interaction" and the best action to take when using prednisone and other medications

- What prednisone is and its side effects

\section{Trigger Exposure}

- Which air quality health index score is a low or high health risk

- The best or worst day to go outside because of the air quality

- The weather conditions for each day

- The best of worst day to go outside because of the weather

Hospital map navigation

- Places on a map

\section{Lifestyle}

\section{Flu prevention}

- The flu shot and its side effects

- When and where to get the fly shot

\section{B Disease specific self-management topics}

\section{Asthma action plan Asthma Only}

- The correct steps to take during a worsening/exacerbation

- The need to continue taking medication despite symptoms

- What to do to prevent an attack/exacerbation

\section{Pulmonary rehabilitation}

COPD Only

- Healthy eating choice and habits

- What a healthy balanced diet contains and why it is important for disease

- Safe tips for exercising

- The features of the program

Figure 2 (A) General Self-management topics. (B) Disease specific self-management topics. 
develop scenarios/passages to assess a person's ability to apply the appropriate skill(s) needed to act in a hypothetical situation related to disease management. The scenarios developed in our HL tool describe typical asthma and COPD self-management situations (as explained above) where the patient faces a problem, and a list of possible response actions by the patient is provided. The items required respondents to read, comprehend, evaluate, and apply the information from the scenario/passage to answer the corresponding questions. A graphic artist designed and drew illustrations for the trigger exposure (a weather forecasting website with air quality health index), hospital map navigation, and breathing control scenarios.

\section{Results}

The following sections summarize the outcome of each tool development stage, as well as the findings from the pretesting of our measurement tool:

1. Systematic Review: The review highlighted the absence of HL tools that had been validated and/or assessed the "communication" domain and uncovered which HL domains were incompletely measured. We found that most of the existing HL tools only assessed the "understand" domain using self-evaluated-based questions, while other HL skills were lacking, in the majority of the tools assessed. We therefore surmised that applying the existing tools lacked the ability to assess all core domains of $\mathrm{HL}$ properly. ${ }^{25}$ We identified two major reasons: (a), the majority of the tools lack the contextual properties of including core HL domains, and (b) the existing tools mainly assess the participant's perception about disease management (self-evaluated approach) vs assessing the participant's actual HL skills via functional-based approach. ${ }^{26}$ The systematic review and work established the need to develop an airways HL measurement tool which comprehensively applied the 5-domain model for asthma/COPD management.

2. Patient-oriented Focus Group: The focus group participants provided useful information that helped to identify 14 topics that challenged them to engage in selfmanagement practices of their health conditions. The participants also helped to create real-life passages (in scenario format) and corresponding 457 items that an asthma or COPD patient might be faced with while managing their disease. Historically, numeracy has been considered by researchers to be a literacy skill, however, the Calgary health literacy charter $(2009)^{37}$ identified that when using HL for health purposes, numeracy is an important variable to consider and, therefore, we included numeracy in our tool.

3. Key-Informant Interviews: These health professionals reviewed and verified the self-management topics identified by the patients during the focus group sessions and the necessary skills that asthma and COPD patient should possess to fully engage in diseasemanagement. In addition, they provided their insights pertaining to relevance of each passage and classified items to each HL core-domain and numeracy.

4. Further Verification of disease-management topics with respiratory physicians: key respiratory opinion leaders helped the team to develop two comprehensive tables pertaining to the optimal selfmanagement skills for asthma and COPD patients and verified the topics and corresponding items that were included in our tool. This allowed us to include the most important disease management in our tool for asthma and COPD patients such as: inhaler technique, prednisone use, flu shot, lifestyle (nutrition and exercise), trigger control, breathing control, and map navigation. This group also provided specific topics for asthma patients (peak flow meters and action plan) and those relevant to COPD patients (pulmonary rehabilitation and mucus control) to be included in our HL tool.

5. Content Review by Professional Educator: With the help of a professional adult patient educator, the information from the needs-assessment stage were applied in the development of a list of "actionoriented" items; combining the HL skills and selfmanagement competencies (herein called Functional HL Skills) that an asthma or COPD patient would need to have, in order, to properly manage their health condition. Patients, key informants, and respirologists who contributed in our tool development process also agreed that addressing patient's numeracy as part of their decision-making process in health care is important, as health and medical information is often presented in mathematical terms, graphs, or tables, and different studies have shown numeracy to directly influence health outcomes. ${ }^{10,17,38,39}$ The tool was formatted into multiple-choice questions consisting of one correct and multiple incorrect response options for each disease-management topic scenario.

6. Pretesting stage: Finally, a new cohort of 75 asthma and COPD patients were asked to respond to the 
tool questions by reviewing the scenarios and entering their selection to the provided questions. They were asked also to provide their comments by writing their suggestions next to each item and scenario. The input of the patients and health professionals at different stages of the study enabled us to further develop our HL tool and cutting down the total number of scenarios/passages to 16 and the items to 96 to be tested in final construct validation stage of the study. This ensured an equal balance of relevant and appropriate items, designed to enable us to distinguish the different HL skills of participants.

The following sections summarize the main findings of the pretesting stage.

1. Barriers to specific HL domains

Participants identified various barriers that prevented them from properly managing their disease. For instance, 15\% of asthma and $6 \%$ of COPD participants perceived "difficulty scheduling an appointment with their doctor" as a barrier to access needed health information and services. In addition, $39 \%$ of asthma and $18 \%$ of COPD patients indicated that "having low confidence in health-care provider" is a major communication barrier with their doctor. Furthermore, $39 \%$ of asthma and $16 \%$ of COPD patients mentioned "receiving inconsistent and conflicting information from different sources (eg, nurse, health educator, and physicians (primary doctor vs specialty doctor))" makes it difficult to apply the received information.

\section{Relevance of self-management topics}

Participants rated the relevance and appropriateness of each self-management topic covered in our HL tool to their daily routine. Table 2 summarized the findings. Overall, the topics covered in our tool were perceived as appropriate by most participants, with more asthma patients than COPD patients finding them relevant and suitable to their daily disease management process. The Flu prevention and Trigger exposure topics were selected as the most relevant vs Action plan and Hospital map/ Navigation topics were deemed the least relevant. Selected participants' quotes related to self-management topics are also provided in Table 3.

\section{Challenges to respond the tool items}

From the items attributed to each self-management topic, those related to assessing health numeracy (which needed calculations without using a calculator) was one of the areas that proved challenging, mainly for COPD patients. One participant indicated: "[It is] a little difficult due to math, I don't know how to respond to these questions" (female, COPD). As an example, around 32\% of asthma and $78 \%$ of COPD participants were unable to calculate the last day to take prednisone based on the given instructions. More information is provided on Table 4.

\section{Discussion and Conclusions}

We identified that there was no currently available HL questionnaire which assesses HL in asthma and COPD patients. Based on this gap in current instruments we followed a comprehensive protocol to develop a valid HL instrument. Key components of the instrument development included extensive involvement of patients and health-care providers. The suggestions provided by patients, key informants and respirologists allowed us to include the most important topics that were common across all participants with asthma and COPD. These topics included the following: inhaler technique, prednisone use, flu shot, lifestyle (nutrition and exercise), trigger control, breathing control, and map navigation. In addition, the respiratory opinion leaders suggested specific topics to be included in out HL tool for asthma patients

Table 2 Relevance of Self-Management Topics

\begin{tabular}{|l|l|l|l|}
\hline & Theme & Asthma (n) & COPD (n) \\
\hline I & Q. Prednisone use passage relevant $(n=50)$ & $39(78 \%)$ & $11(22 \%)$ \\
2 & Q. Flu prevention passage relevant $(n=52)$ & $41(79 \%)$ & $11(21 \%)$ \\
3 & Q. Hospital map navigation passage relevant $(n=23)$ & $16(70 \%)$ & $7(30 \%)$ \\
4 & Q. Trigger exposure (eg, weather and air quality) passage relevant $(n=44)$ & $35(79 \%)$ & $9(21 \%)$ \\
5 & Q. Inhaler use passage relevant $(n=49)$ & $38(78 \%)$ & $11(22 \%)$ \\
6 & Q. Action plan passage relevant $(n=16)$ & $13(81 \%)$ & $3(19 \%)$ \\
\hline
\end{tabular}


Table 3 Selected Participants' Quotes on Self-Management Topics

\begin{tabular}{|c|c|}
\hline Hospital map navigation & $\begin{array}{l}\text { "[The map] is not relevant, not helpful, [assessing] navigation is not necessary. Things [locations] just need to } \\
\text { be clearly labelled in hospitals and they [patients] will get it." - Asthma } \\
\text { "I hate the map; what relevance does it have?" - Asthma }\end{array}$ \\
\hline Action plan & $\begin{array}{l}\text { "I have [an] action plan but I'm not sure if I should use it or if I should follow it properly because once I had } \\
\text { flare up and I think it was not helpful. I don't remember where I put it [action plan]." - COPD } \\
\text { "I like the action plan. I think this really helped me, with medication." - Asthma }\end{array}$ \\
\hline Prednisone use & $\begin{array}{l}\text { "I don't like how it [prednisone] makes your heartbeat rise and I don't know how prednisone is made. } \\
\text { Prednisone does have a lot of drawbacks with only a few positives." - Asthma } \\
\text { "Some people are on prednisone forever, it's an awful way to live. It's horrible. I never slept for three months, } \\
\text { there's no sleeping. Weight gain, yeah, I swell up, it was horrible." - COPD }\end{array}$ \\
\hline Flu prevention & $\begin{array}{l}\text { "I don't think l've ever really discussed flu prevention as something to pay specific attention to, with someone } \\
\text { with asthma." - Asthma } \\
\text { "I cannot get the flu. I mean, I can't get the flu, it's dangerous for me, the flu will kill me, so I'm very careful. } \\
\text { I get the flu shot, I wash my hands, I do all the stuff, avoid crowds, try not to fly, flight is the worst, contained } \\
\text { spaces." - COPD }\end{array}$ \\
\hline $\begin{array}{l}\text { Trigger exposure (eg, weather } \\
\text { and air quality) }\end{array}$ & $\begin{array}{l}\text { "I mean, I hear it on the radio, so I wouldn't say that I don't monitor it but I don't do anything." - COPD } \\
\text { "If there's a weather forecast, sometimes it will talk about pollen counts for seasonal allergies, it will talk about } \\
\text { smog alerts, for people with respiratory issues [they] should stay home today. So, I, I do not seek those out } \\
\text { but if it comes, if those kinds of warnings come with } \\
\text { the weather I do pay attention to those." - Asthma }\end{array}$ \\
\hline Peak flow meter use & $\begin{array}{l}\text { "If peak flow is bad, go see the doctor right away." - Asthma } \\
\text { "I used the thing that you blow into and it tells you how much you blow out. I had one of those for years." - } \\
\text { Asthma }\end{array}$ \\
\hline Inhaler use & $\begin{array}{l}\text { "For my understanding, there's a bit of confusion whenever it comes to instructions on taking medication. It's } \\
\text { usually the pharmacist, because they ask you have you taken this before, and then, when I had a new form of } \\
\text { inhaler or something that I had never used, they would demonstrate it. So yeah, l've never really had that." - } \\
\text { Asthma } \\
\text { "Okay. Um, those [inhaler use] were good questions." - Asthma }\end{array}$ \\
\hline $\begin{array}{l}\text { Lifestyle (eg, healthy eating and } \\
\text { exercise) }\end{array}$ & $\begin{array}{l}\text { "I don't know that I would talk about diet, and mentioned exercise but not in specifics about I want to do this, } \\
\text { so can we come up with a plan for me to be able to stabilize me being active?" - Asthma } \\
\text { "If a person wants to make a lifestyle change, they have to put in the effort. The person has to really commit } \\
\text { to that." - Asthma }\end{array}$ \\
\hline
\end{tabular}

(peak flow meters and action plan) and those relevant to COPD patients (pulmonary rehabilitation and mucus control) to be included in our HL tool. Current literature confirms that existing HL measurement tools related to asthma and COPD lack patient input in their development stages and also functional-based items, to measure the important components of HL and numeracy skills. Such deficiencies were reported by various studies summarized in our systematic review and researchers both from clinical and HL fields challenge the practical ability of such tools to assess the link between HL and self-management process. $^{25,26}$ To address these issues, we engaged patients and health professionals from the initial stages of our tool development study; specifically to provide their insights regarding the content, format, relevance, and clarity of the development scenarios and items for each asthma and COPD disease management topics. ${ }^{28,29}$

We found the results of the needs assessment study were not only useful for guiding the development of our proposed HL tool but also helped to identify possible gaps in respiratory disease management research. Our participants reported several barriers for engaging in selfmanagement practices, which are consistent with those found in the literature ${ }^{40-43}$ including improper communication with health-care providers and difficulty accessing and understanding health-related information. Utilizing medical jargon and unfamiliar terminology (in verbal or written communication) by health-care providers, in 
Table 4 Correct Responses to Items

\begin{tabular}{|c|c|c|c|}
\hline & & Asthma (n) & COPD (n) \\
\hline Prednisone use & $\begin{array}{l}\text { Q. Calculate the last day to take prednisone }(n=4 I) \\
\text { Q. Calculate the day to call doctor }(n=\mid 2)\end{array}$ & $\begin{array}{l}32(78 \%) \\
11(92 \%)\end{array}$ & $\begin{array}{l}9(22 \%) \\
\text { I ( }(8 \%)\end{array}$ \\
\hline Inhaler use & $\begin{array}{l}\text { Q. Calculate the time to take the next puffs }(n=58) \\
\text { Q. Calculate the total number of puffs ( } n=31)\end{array}$ & $\begin{array}{l}46(79 \%) \\
26(84 \%)\end{array}$ & $\begin{array}{l}12(21 \%) \\
5(16 \%)\end{array}$ \\
\hline Hospital map navigation & $\begin{array}{l}\text { Q. Identify the closest entrance to the Lung Centre }(n=54) \\
\text { Q. Identify the two places would pass by if took the shortest route from the } \\
\text { Lung Centre to the pharmacy }(n=4 I) \\
\text { Q. Identify elevator would pass by on way from the Pulmonary Function Lab } \\
\text { to the pharmacy }(n=2 I)\end{array}$ & $\begin{array}{l}40(74 \%) \\
33(80 \%) \\
18(86 \%)\end{array}$ & $\begin{array}{l}14(26 \%) \\
8(20 \%) \\
3(14 \%)\end{array}$ \\
\hline Flu prevention & $\begin{array}{l}\text { Q. Identify whether there are severe side } \\
\text { effects to the flu shot }(n=45)\end{array}$ & $34(76 \%)$ & II (24\%) \\
\hline $\begin{array}{l}\text { Trigger exposure (eg, healthy } \\
\text { eating and exercise) }\end{array}$ & Q. Identify the worst day to go outside because of the air quality $(n=40)$ & $28(70 \%)$ & $12(30 \%)$ \\
\hline $\begin{array}{l}\text { Lifestyle (eg, healthy eating and } \\
\text { exercise) }\end{array}$ & $\begin{array}{l}\text { Q. Calculate the maximum number of pancakes to eat based on suggested } \\
\text { daily intake of sugar }(n=17)\end{array}$ & $14(82 \%)$ & $3(18 \%)$ \\
\hline
\end{tabular}

addition to patients' failure to communicate their questions or concerns, were inevitably reported by different studies as major obstacles to appropriate engagement in diseasemanagement process. ${ }^{41,42,44-46}$ Around $70 \%$ of patients in our study indicated they knew their limitations such as lack of transportation, lack of speaking the same language that the physician, lack of education in their disease, etc., however, many of them also stated they felt reluctant to express their concerns or ask questions, due to the short visit time or attitude of the care provider. In addition, more than half of our study participants reported having low confidence in their health-care provider's interest to listen or respond their questions, preventing proper communication with their care provider. Provision of inconsistent health information by various sources was also mentioned as another issue of concern. For instance, participants mentioned they often felt confused when receiving conflicting information from the pharmacist, doctor, nurse, or internet, and that they did not know how to accurately interpret and evaluate the information before applying it. Similar findings have also been reported previously. ${ }^{47,48}$

As we predicted, most of the self-management topics covered in our tool were considered relevant, mainly because we applied the patients' and health professionals' suggestions during our tool development process. However, we noticed the action plan topic was perceived as one of the least relevant subjects for some participants, in particular the COPD patients. Although the effectiveness and practicability of the benefits of COPD action plans are uncertain and still under investigation, ${ }^{49,50}$ an action plan is a critical component of asthma self-management, and has a robust evidence base for its efficacy. ${ }^{3,4,51}$ However, various studies have reported only a minority of asthma patients receive an action plan from their doctor or respiratory educator (access), and for those who do receive an action plan, only approximately $50 \%$ use it appropriately. ${ }^{52-56}$ Based on our participants' feedback, poor action plan utilization may be mainly due to having difficulty in following the information provided on their action plan. As suggested by other researchers, when patients received proper instructions on how to follow their action plan, they viewed it more favorably and useful. ${ }^{54,55}$ Similar findings were reported by other researchers that applied the patients' feedback and suggestions in the development of pictorial or friendly-user action plans. ${ }^{51-54}$ In addition, understanding and evaluation of the information provided on the action plan (which has implications for "use" domain), could also be a major factor of not using the instructions provided by the doctor. Therefore, detailed communication of the proper use of an action plan from the providers' side is needed also in addition to providing the patient with the option of calling the provider when there is uncertainty of when it should be used (evaluation).

To minimize the complexity of using disease-related information, our participating key informants and respirologists suggested simplifying the information by using fewer and simpler words with easy-to-understand instructions 
(possibly supplemented by colored diagrams and pictures) Therefore, we applied graphical features and illustrations to supplement plain language in the development of our tool's passages/scenarios and items. Several studies have also reported that using colored and pictorial formats with plain language texts can improve asthma information, possibly influencing better self-management and asthma outcomes. ${ }^{52,55}$ Lastly, the hospital map navigation topic was perceived as one of the least relevant topics with many asthma and COPD participants; stating that it may not be related to their disease management. In contrary, we believe this is a relevant topic to the "access" domain of HL, as mentioned by other researchers in this field ${ }^{36,37}$. McCormack et $\mathrm{al}^{57}$ and Sun et $\mathrm{al}^{58}$ also included the hospital map navigation as a topic in their skill-based HL measurement tool. The foundation of including map navigation items in a HL tool was to demonstrate the link between the ability to read, find, and understand information on the map, in order to access needed services. ${ }^{38,57}$ Applying the information and comments received from the participants during the pretesting stage enabled our team to modify the HL tools that we developed for final validation with new cohort of asthma and COPD patients across Canada.

\section{Limitations}

This study was conducted among English and Frenchspeaking subjects in Canada, and our findings might not be generalizable to countries with different health systems. As recruitment was conducted through respiratory clinics, participants would be expected to have both a more severe disease and a higher likelihood of exposure to previous disease education (including self-management education), possibly indicating a smaller expected HL gap compared to the general population of asthma and COPD patients.

\section{Conclusions and Implications}

Recent studies have concluded that the exiting HL measurement tools usually provide limited information about HL skills of patient population groups, as they only establish the association between HL skills and health status. Thus, to address the effect of HL on health outcomes we need valid and reliable measures of HL. We have involved patients and health professionals in the design and development process of our multifacetted functional-based HL tool. Their engagement enabled us to assess the content and face validation before pilot testing the tool with a new cohort of patients. The clarity and relevance of the scenarios and items were checked with respirologists and health literacy experts and necessary modifications were applied from the suggestions received from our participants. This HL tool is currently being validated among a larger number of adult asthma and COPD patients across Canada to check its reliability and validity and develop HL scores that would help clinicians and researchers to assess the HL level of their clients. We anticipate that our tool will serve as a first ever validated HL tool for this patient population group. Our next steps will include developing the finalized tool and subsequently address issues of reliability, responsiveness in an interventional study as well as addressing its utility in other languages.

\section{Highlights}

- Patients perceived communication as a barrier to proper self-management

- Flu prevention was the most relevant self-management topic for asthma/COPD patients

- Hospital map navigation was the least relevant topic for asthma/COPD patients

- Inhaler use items were correctly responded to compared to action plan items

- Feedback received has been applied in the further testing of a health literacy tool

\section{Acknowledgments}

We would like to thank all asthma and COPD patients for their involvement in this study as well as express thanks to Brenda Kwan, Selva Bayat, Darrin Wiebe, Nilou Aran, and Iris van der Heide who helped us in the data collection, coding, and analyses of the pretesting stage of the study at the Vancouver site.

The abstract of this paper was presented at the 2018 Oregon and SW Washington Health Literacy Conference name 'Enhancing Equity, Improving Health' as a poster presentation with interim findings. The poster's abstract was published in Legacy Health Literacy Website: https:// twitter.com/OurLegacyHealth.

\section{Funding}

This work was supported by the Canadian Institutes of Health Research (CIHR).

\section{Disclosure}

Dr Samir Gupta reports grants from Canadian Institutes of Health Research during the conduct of the study. The authors report no other conflicts of interest in this work. 


\section{References}

1. Rootman I, Gordon-El-Bihbety D A vision for a health literate Canada report of the Expert Panel on Health Literacy. Canadian Public Health Association (CPHA); 2008. Retrieved from: https://www.cpha.ca/visionhealth-literate-canada-report-expert-panel-health-literacy. Accessed 4 July 2019.

2. World Health Organization (WHO). The mandate for health literacy. 9th global Health Promotion Conference. Shanghai; 2016. Available from: https://www.who.int/healthpromotion/conferences/9gchp/ health-literacy/en/. Accessed January 05, 2020.

3. Global Initiative for Asthma (GINA). Global strategy for asthma management and prevention. Report; 2019. Available from: https:// ginasthma.org/wp-content/uploads/2019/04/GINA-2019-main-Pocket -Guide-wms.pdf. Accessed September 20, 2019.

4. Global Initiative for Chronic Obstructive Lung Disease (GOLD) Global strategy for the diagnosis, management, and prevention of chronic obstructive pulmonary disease (COPD). Global Initiative for Chronic Obstructive Lung Disease (2019 report); 2019. Available from: https:// goldcopd.org/wp-content/uploads/2018/11/GOLD-2019-v1.7-FINAL14Nov2018-WMS.pdf. Accessed September 20, 2019.

5. Canadian Public Health Association (CPHA). An inter-sectoral approach for improving health literacy for Canadians. 2012. Available from: https:// phabc.org/w p - content/upload s/2015/09/ IntersectoralApproachforHealthLiteracy-FINAL.pdf. Accessed January 05, 2020.

6. Poureslami I, Rootman I, Pleasant A, FitzGerald JM. The emerging role of health literacy in chronic disease management: the response to a call for action in Canada. Popul Health Manag. 2016;19 (4):230-232. doi:10.1089/pop.2015.0163

7. Gazmararian JA, Williams MV, Peel J, Baker DW. Health literacy and knowledge of chronic disease. Patient Educ Couns. 2003;51 (3):267-275. doi:10.1016/S0738-3991(02)00239-2

8. Roberts NJ, Ghiassi R, Partridge MR. Health literacy and COPD. Int J Chron Obstruct Pulmon Dis. 2008;3(4):499-507. doi:10.2147/ copd.s1088

9. Thai AL, George M. The effects of health literacy on asthma self-management. $J$ Asthma Allergy Educ. 2010;1(2):50-55. doi: $10.1177 / 2150129710368850$

10. Peters E, Meilleur L, Tompkins MK Numeracy and the affordable care act: opportunities and challenges. Institute of Medicine (IOM): Health Literacy and Numeracy Workshop Summary; The National Academies Press; Washington, DC; 2001.

11. Jordan JE, Osborne RH, Buchbinder R. Critical appraisal of health literacy indices revealed variable underlying constructs, narrow content and psychometric weaknesses. J Clin Epidemiol. 2011;64 (4):366-379. doi:10.1016/j.jclinepi.2010.04.005

12. Chinn D. Critical health literacy: a review and critical analysis. Soc Sci Med. 2011;73(1):60-67. doi:10.1016/j.socscimed.2011.04.004

13. Baker DW. The meaning and the measure of health literacy. J Gen Intern Med. 2006;21(8):878-883. doi:10.1111/j.15251497.2006.00540.x

14. Collins SA, Currie LM, Bakken S, et al. Health literacy screening instruments for eHealth applications: a systematic review. J Biomed Inform. 2012;45:598-607. doi:10.1016/j.jbi.2012.04.001

15. Kwan B, Frankish J, Rootman I The development and validation of measures of "health literacy" in different populations. UBC Institute for Health Promotion press; 2006. Available from: http://blogs.ubc.ca/frank ish/files/2010/12/HLit-final-report-2006-11-24.pdf. Accessed July 3, 2019.

16. Chinn D, McCarthy C. All Aspects of Health Literacy Scale (AAHLS): developing a tool to measure functional, communicative and critical health literacy in primary healthcare settings. Patient Educ Couns. 2013;90(2):247-253. doi:10.1016/j. pec.2012.10.019
17. Kiechle ES, Bailey SC, Hedlund LA, et al. Different measures, different outcomes? A systematic review of performance-based versus self-reported measures of health literacy and numeracy. $J$ Gen Intern Med. 2015;30:1538-1546. doi:10.1007/s11606-015-3288-4

18. Pleasant A, McKinney J. Coming to consensus on health literacy measurement: an online discussion and consensus-gauging process. Nurs Outlook. 2011;59:95-106. doi:10.1016/j.outlook.2010.12.006

19. Poureslami I, Rootman I, Pleasant A, et al. The emerging role of health literacy in chronic disease management: the response to a call for action in Canada. Popul Health Manag. 2016;19:230-231. doi:10.1089/pop.2015.0163

20. Hawkins M, Gill SD, Batterham R, et al. The Health Literacy Questionnaire (HLQ) at the patient-clinician interface: a qualitative study of what patients and clinicians mean by their HLQ scores. BMC Health Serv Res. 2017;17:309-324. doi:10.1186/s12913-0172254-8

21. Parmer J, Furtado D, Rubin DL, et al. Improving interactive health literacy skills of older adults: lessons learned from formative organizational research with community partners. Prog Community Health Partnersh. 2015;9(4):531-536. doi:10.1353/cpr.2015.0071

22. Pugh W, Porter AM. How sharp can a screening tool be? A qualitative study of patients' experience of complete a bowel cancer screening questionnaire. Health Expect. 2011;14(2):170-177. doi:10.1111/j.1369-7625.2010.00629.x

23. Poureslami I, Pakhale S, Lavoie K, et al. Patients as research partners in chronic obstructive pulmonary disease and asthma research: priorities, challenges and recommendations from asthma and COPD patients. Can J Respir Crit Care. 2018;2(3):138-146.

24. Nutbeam D. The evolving concept of health literacy. Soc Sci Med. 2008;67:2072-2078. doi:10.1016/j.socscimed.2008.09.050

25. Shum J, Poureslami I, Doyle-Waters MM, FitzGerald JM. The application of health literacy measurement tools (collective or individual domains) in assessing chronic disease management: a systematic review protocol. Syst Rev. 2016;5:97-105. doi:10.1186/s13643-016-0267-8

26. Shum J, Poureslami I, Wiebe D, et al. Airway diseases and health literacy (HL) measurement tools: a systematic review to inform respiratory research and practice. Patient Educ Couns. 2018;101 (4):596-618. doi:10.1016/j.pec.2017.10.011

27. Institute of Medicine. Measures of health literacy: workshop summary. National Academies Press; 2009. Available from: https:// www.ncbi.nlm.nih.gov/books/NBK45384/pdf/Bookshelf_ NBK45384.pdf. Accessed January 10, 2020.

28. Shum J, Poureslami I, FitzGerald JM Involvement of patients and professionals in the development and pretesting of an asthma/chronic obstructive pulmonary disease (COPD) health literacy (HL) measurement tool: a Canadian approach. Poster presentated at: Oregon and SW Washington Health Literacy Conference; 2018.

29. Shum J, Poureslami I, Wiebe D, et al. Bridging the gap: key informants' perspectives on patient barriers in asthma and COPD selfmanagement and possible solutions. Can J Respir Crit Care. 2019. doi:10.1080/24745332.2019.1582307

30. Wiebe D, FitzGerald FM, Shum J, et al. A preliminary framework for the development of a health literacy measurement tool for asthma and COPD. Chest. 2016;150(4):633A. doi:10.1016/j.chest.2016.08.725

31. Forman J, Damschroder L. Qualitative content analysis. Biotechnol Adv. 2015;11:39-62.

32. Bengtsson M. How to plan and perform a qualitative study using content analysis. NursPlus. 2016;2:8-14.

33. Vaismoradi M, Turunen H, Bondas T. Content analysis and thematic analysis: implications for conducting a qualitative descriptive study. Nurs Health Sci. 2013;15:398-405. doi:10.1111/nhs. 12048

34. Morgado FFR, Meireles JFF, Neves CM, et al. Scale development: ten main limitations and recommendations to improve future research practices. Psicol Reflex Crit. 2018;30:3. doi:10.1186/s41155-0160057-1 
35. Hinkin TR. A review of scale development practices in the study of organizations. J Manag. 1995;21:967-988.

36. McDaniel MA, Nguyen NT. Situational judgment test: a review of practice and construct assessed. Int J Sel Assess. 2001;9:103-113. doi:10.1111/1468-2389.00167

37. Coleman C, Kurtz-Rossi S, Rootman I, et al. The calgary charter on health literacy: rationale and core principles for the development of health literacy curricula. The Centre for Literacy; 2009. Available from: http://www.centreforliteracy.qc.ca/sites/default/files/CFL Calgary_Charter_2011.pdf. Accessed January 05, 2020.

38. Berkman N, Sheridan KE, Donahue D, et al. Health Literacy Interventions and Outcomes: An Updated Systematic Review. RTI International Press; 2011.

39. Pleasant A. Advancing health literacy measurement: a pathway to better health and health system performance. J Health Commun. 2014;19:1481-1496. doi:10.1080/10810730.2014.954083

40. Miles C, Arden-Close E, Thomas M, et al. Barriers and facilitators of effective self-management in asthma: systematic review and thematic synthesis of patient and healthcare professional views. NPJ Prim Care Respir Med. 2017;27:57-63. doi:10.1038/s41533-017-0056-4

41. Hillebregt CF, Vlonk AJ, Bruijnzeels MA, van Schayck OCP, Chavannes NH. Barriers and facilitators influencing self-management among COPD patients: a mixed methods exploration in primary and affiliated specialist care. Int J Chron Obstruct Pulmon Dis. 2017;12:123-133. doi:10.2147/COPD.S103998

42. Russell S, Ogunbayo OJ, Newham JJ, et al. Qualitative systematic review of barriers and facilitators to self-management of chronic obstructive pulmonary disease: views of patients and healthcare professionals. NPJ Prim Care Resp M. 2018;28(1):2-9. doi:10.1038/s41533-017-0069-z

43. Kyle S, Shaw D. Doctor-patient communication, patient knowledge and health literacy: how difficult can it all be? Ann R Coll Surg Engl. 2014;96:e9-e13. doi:10.1308/rcsbull.2014.96.6.e9

44. Adams RJ. Improving health outcomes with better patient understanding and education. Risk Manag Health Policy. 2010;3:61-72. doi:10.2147/RMHP.S7500

45. McCray AT. Promoting health literacy. $J$ Am Med Inform Assoc. 2005;12(2):152-163. doi:10.1197/jamia.M1687

46. Schillinger D, Piette J, Grumbach K, et al. Closing the loop: physician communication with diabetic patients who have low health literacy. Arch Intern Med. 2003;163(1):83-90. doi:10.1001/ archinte.163.1.83
47. Carpenter DM, Geryk LL, Chen AT, Nagler RH, Dieckmann NF, Han PKJ. Conflicting health information: a critical research need. Health Expect. 2016;19(6):1173-1182. doi:10.1111/hex.12438

48. Carpenter DM, DeVellis RF, Fisher EB, DeVellis BM, Hogan SL, Jordan JM. The effect of conflicting medication information and physician support on medication adherence for chronically ill patients. Patient Educ Couns. 2010;81(2):169-176. doi:10.1016/j. pec.2009.11.006

49. Trappenburg JC, Monninkhof EM, Bourbeau J, et al. Effect of an action plan with ongoing support by a case manager on exacerbation-related outcome in patients with COPD: a multicentre randomized controlled trial. Thorax. 2011;66(11):977-984. doi:10.1136/thoraxjnl-2011-200071

50. Sedeno MF, Nault D, Hamd DH, Bourbeau J. A self-management education program including an action plan for acute COPD exacerbations. COPD. 2009;6(5):352-358. doi:10.1080/15412550903150252

51. Canadian Thoracic Society 2012 guideline update. Asthma action plan. Available from: https://machealth.ca/programs/asthma-actionplan/m/resources/1037. Accessed September 20, 2019.

52. Beauchesne M, Levert V, Tawil ME, Labrecque M, Blais L. Action plans in asthma. Can Respir J. 2006;13(6):306-310. doi:10.1155/ 2006/458658

53. Yin HS, Gupta RS, Tomopoulos S, et al. A low-literacy asthma action plan to improve provider asthma counseling: a randomized study. Pediatrics. 2016;137(1):e20150468. doi:10.1542/peds.2015-0468

54. Pur Ozyigit L, Ozcelik B, Ozcan Ciloglu S, Erkan F. The effectiveness of a pictorial asthma action plan for improving asthma control and the quality of life in illiterate women. J Asthma. 2014;51 (4):423-428. doi:10.3109/02770903.2013.863331

55. Gupta S, Wan FT, Hall SE, Straus SE. An asthma action plan created through physician, educator, and patient online collaboration with usability and visual design optimization. Respiration. 2012;84 (5):406-415. doi:10.1159/000338112

56. Roberts NJ, Mohamed Z, Wong P, Johnson M, Loh L, Partridge MR. The development and comprehensibility of a pictorial asthma action plan. Patient Educ Couns. 2009;74(1):12-18. doi:10.1016/j.pec.2008.07.049

57. McCormack L, Bann C, Squiers L, et al. Measuring health literacy: a pilot study of a new skills- based instrument. J Health Commun. 2010;15(Suppl 2):51-71. doi:10.1080/10810730.2010.499987

58. Sun X, Chen J, Du W, et al. Measuring health literacy regarding infectious respiratory diseases: a new skills-based instrument. PLoS One. 2013;8(5):e64153. doi:10.1371/journal.pone.0064153

\section{Publish your work in this journal}

The International Journal of COPD is an international, peer-reviewed journal of therapeutics and pharmacology focusing on concise rapid reporting of clinical studies and reviews in COPD. Special focus is given to the pathophysiological processes underlying the disease, intervention programs, patient focused education, and self management protocols. This journal is indexed on PubMed Central, MedLine and CAS. The manuscript management system is completely online and includes a very quick and fair peer-review system, which is all easy to use. Visit http://www.dovepress.com/testimonials.php to read real quotes from published authors. 